\title{
Estimation of Default Probabilities: Application of the Discriminant Analysis and the Structural Approach for Companies Listed on the BVC
}

\author{
Lahsen Oubdi, Abdessamad Touimer \\ Laboratory of Industrial Engineering and Computer Science, National School of Applied Sciences (ENSA), Agadir, Morocco \\ Email: 1.oubdi@uiz.ac.ma, Abdessamad.touimer@edu.uiz.ac.ma
}

How to cite this paper: Oubdi, L., \& Touimer, A. (2017). Estimation of Default Probabilities: Application of the Discriminant Analysis and the Structural Approach for Companies Listed on the BVC. Journal of Financial Risk Management, 6, 285-299. https://doi.org/10.4236/jfrm.2017.63021

Received: August 2, 2017

Accepted: September 5, 2017

Published: September 8, 2017

Copyright $\odot 2017$ by authors and Scientific Research Publishing Inc. This work is licensed under the Creative Commons Attribution International License (CC BY 4.0). http://creativecommons.org/licenses/by/4.0/

\begin{abstract}
This article aims to compare the calculated results of the structural approach (Internal Ratings-Based IRB) and the discriminant analysis (Z-score of Altman, 1968), based on data from companies listed on the BVC for the period from 02 January 2014 to December 31, 2014. The structural approach is directly linked to the economic reality of the company; the default takes place as soon as the market value of these assets falls below a certain threshold. The major constraint for this approach is the determination of the probabilities of default. This situation is overcome by using the Black \& Scholes (1973) model, based on Monte Carlo simulations. While the Z-score method is a financial analysis technique of business failure predictions, which is based on financial and economic ratios.
\end{abstract}

\section{Keywords}

Credit Risk, IRB Approach, Z-Score, Monte Carlo Simulation, Default Probability

\section{Introduction}

The evolution of banking activity in recent years, and after the subprime crisis, makes the management of credit risks an important issue. In June 2014, Bank Al-Maghrib's (BAM) prudential regulations accompanying the adoption of the Basel III standard came into force in order to strengthen the financial strength of credit institutions, Basel Committee on Banking Supervision (2015).

It is clear that several types of risks (market, credit and operational ...) can affect any bank. Credit risk, known as counterparty risk, is defined as the risk that a borrower could default on its liabilities: whether he is unable to keep his promise to pay the interest on time or to repay the principal to on the deadline. 
Indeed, the Basel II Committee considered that credit risk is the most important risk of a bank, since it considered that for a bank, credit risk represents between $75 \%$ and $90 \%$ of the total risk. In addition to the BAM circular, this obliges banks to use the IRB method in their credit risk information systems. The major challenge for estimating this risk for banks is the calculation of probabilities of default. In this paper, we propose a methodology for estimating these probabilities of default and thus allow potential lenders to apply the internal evaluation methods (Z-score or IRB), Basel Committee on Banking Supervision (2011).

As a result, banks are very interested in developing and applying internal evaluation models of credit risk, including the calculation of probability of default in order to optimize the return on loans granted.

The general purpose of our work is to assess and analyze the level of credit risk of companies listed on the stock exchange of Casablanca (BVC). In order to achieve our objectives, we have formulated two (2) hypotheses:

Hypothesis 1: The market value of companies listed on the BVC is negatively correlated with the probability of default;

Hypothesis 2: The business sector is a level risk determining factor.

To verify these hypotheses we apply risk assessment methods to a sample of 22 listed companies over the period from January the $2^{\text {nd }}, 2014$ to December the $31^{\text {st }}, 2014$ : the IRBF method and the scoring system representing internal rating approaches.

To carry out this research, our work consists of two (2) parts:

The first will be devoted to the theoretical approach of measuring credit risk. The second part will focus on the evaluation of credit risk in Moroccan listed companies on the BVC.

\section{Theoretical Credit Risk Assessment Models}

Credit risk is one of the most important risks faced by credit institutions. Its mastery rests on the establishment of clear identification, assessment and coverage procedures. It is evaluated according to the various methods which are the discrimination analysis (Z-Score) and the structural approach (IRBF).

\subsection{Credit Risk: Assessment of Probabilities of Default}

Under Basel II, banks are free to use their own default probability model (historical, from bond prices or from share prices).

\subsubsection{Probability of Historical Defect}

For a good illustration, we use data provided by rating agencies such as moody's. They show the default rates evolution according to a given horizon for a company (or bond) placed at the beginning of the period at a given rating level. Table 1 shows that an obligation rated Baa has a $0.2 \%$ probability to default in the year and a $0.57 \%$ probability to default within two years, hence the probability for an obligation to default the second year is $0.57 \%-0.20 \%=0.37 \%$. 
Table 1. Cumulative default probability in \%, 1970-2003.

\begin{tabular}{ccccccc}
\hline \multirow{2}{*}{ Notation } & \multicolumn{7}{c}{ Years/Maturity } \\
\cline { 2 - 7 } & $\mathbf{1}$ & $\mathbf{2}$ & $\mathbf{3}$ & $\mathbf{1 0}$ & $\mathbf{1 5}$ & $\mathbf{2 0}$ \\
\hline Aaa & 0.00 & 0.00 & 0.00 & 0.62 & 1.21 & 1.55 \\
$\mathrm{Aa}$ & 0.02 & 0.03 & 0.06 & 0.68 & 1.51 & 2.70 \\
$\mathrm{~A}$ & 0.02 & 0.09 & 1.23 & 1.59 & 2.94 & 5.24 \\
$\mathrm{Baa}$ & 0.20 & 0.57 & 1.03 & 5.10 & 9.12 & 12.59 \\
$\mathrm{Ba}$ & 1.26 & 3.48 & 6.00 & 21.01 & 30.88 & 38.56 \\
B & 6.21 & 13.67 & 20.65 & 50.02 & 59.21 & 60.73 \\
$\mathrm{Caa}$ & 23.65 & 37.20 & 48.02 & 77.91 & 80.23 & 80.23 \\
\hline
\end{tabular}

According to Table 1, the probability of default shows that, for the investment category, it tends to be an increasing function of the horizon. For example, the probability of default in class "A" at 1,2 or 3 years is $0.02 \%, 0.07 \%(0.09 \%-$ $0.02 \%=0.07 \%$ ), and $0.14 \%$, respectively. This is due to the fact that the borrower is initially considered to be low risk and that, over time, the possibility of deteriorating creditworthiness is increasing. On the contrary, for the speculative category, the probability of default is often a decreasing function of the horizon. For example, the probability of default in class "Caa" at 1,2 or 3 years is $23.65 \%$, $13.55 \%$ and 10.82\%, respectively, Bank Al-Maghrib (2006).

\subsubsection{Probability of Default from Bond Prices}

The probability of default of an enterprise can be estimated from its obligations (1). Generally, we can write:

$$
P D=\frac{S}{1-R}
$$

where $P D$ is probability of default, $S$ represent spread between corporate and risk-free bond and $R$ is recovery anticipated rate.

\subsubsection{Probability of Default on the Basis of Share Prices}

Some analysts have turned back to stock prices which offer relevant information on default probabilities better than rating agencies. It is essential to know for each loan the amount of Exposure at Default $(E A D)$. Following the default, the loss incurred will be less than the $E A D$ because the lender obtains a recovery $R$ non-zero on this loan. The model-building of the loss on a loan thus passes by the estimation of the Loss Given Default $(L G D=1-R)$.

This information on the amplitude of losses must be supplemented by information on the frequency of defects (loan maturity for example), considered in the calculation of the probability of default.

The product of the loss given default and the exposure at default is called the severity of the loss, which is also a random variable. So, the loss $(L)$ to come is a random variable (2) equal to the product of the severity of the loss and the variable indicating of default: 


$$
L=E A D \times L G D \times I_{D}=S E V \times I_{D}
$$

where $I_{D}$ is the indicating variable of default and $S E V$ the severity of the loss random variable. These three risk parameters that characterize a loan $(E A D$, $L G D$ and $P D$ ) are used to estimate the Expected Loss $E(L)$ (3) and unexpected Loss $(U L)(5)$ which is the standard deviation of the loss. We calculate the Expected Loss and variance on the loan as:

$$
\begin{gathered}
E(L)=L G D \times E A D \times P D \\
\operatorname{var}(L)=E\left(L^{2}\right)-(E(L))^{2}=L G D^{2} \times E A D^{2} \times P D-L G D^{2} \times E A D^{2} \times P D^{2} \\
=L G D^{2} \times E A D^{2} \times P D(1-P D) \\
U L=\sigma(L)=\sqrt{\operatorname{var}(L)}=L G D \times E A D \times \sqrt{P D(1-P D)}
\end{gathered}
$$

\subsection{The Regulation of Credit Risk}

The regulations governing the notion of credit risk in Moroccan banks are inspired by the requirements of Basel and those of Bank AL-Maghrib.

\subsubsection{Basel Requirements for Credit Risk}

In July, the Basel Committee on Banking Supervision (1988) developed the international solvency ratio, known as the COOKE ratio (Basel I). It defines the capital requirements that banks must meet according to the risks taken. This ratio relates regulatory capital to weighted assets which must be at least $8 \%$.

Against the evolution of credit risks, the Cooke ratio scheme showed a large limit linked to the definition of credit commitments. The main considered variable was the amount of distributed credit.

It appears, in the light of modern financial theory, that the essential dimension of the borrower's credit-worthiness is neglected, and thus of the credit risk that it really represents. For example, the Basel Committee on Banking Supervision (2004) proposed a new set of recommendations that defines a more effective measure of credit risk, through a system of internal ratings that is specific to each institution (Internal Rating Based) as well as the new solvency ratio, with McDonough's ratio considering operational risk so that the bank's own funds $>8 \%$.

These Basel II recommendations are based on three complementary pillars:

The first focuses on the supervisory review process, the second on minimum capital requirements and the latter on market discipline, but only the first one will be addressed in this research.

It refines the 1988 agreement and seeks to make the equity consistent with the risks really incurred by financial institutions. The news mentions the consideration of operational risks (fraud and system failure, etc.) and market risks, in addition to the credit risk or the counterparty.

For credit risk, credit institutions may use different external or internal valuation mechanisms. The standard method, which is using ratings provided by external organizations (Moody's, Standard \& Poor, Fitch, etc.). For internal ratings based (IRB) approaches, they are founded on the credit risk determination by 
the credit institution itself, through the allocation of an individual rating to their clients benefiting from appropriations, based on the internal estimations related to the following risk components, foreseen by Basel II, namely:

- Measurement of Probability of Default;

- Loss Given Default;

- Effective maturity;

- Exposure at Default.

It should be noted that if the rating of the customer and the probability of default are determined in the internal rating based (IRB) approaches by the credit institution itself, the parameters of the other three components are either provided by the national supervisory authority of the credit institutions (in the framework of the IRB Foundation or simple) or established by the bank or the financing company itself (in the case of advanced, more complex IRB).

\subsubsection{BAM's Requirements for Credit Risk According to Basel III}

Six years after the introduction of Basel II, the Central bank of Morocco (BAM_ transposed in August 2013, in application of the new Basel III framework, the latest capital standards and the Liquidity Coverage Ratio, known as LCR.

Following the publication by the Basel Committee in September 2012, of the revision of the fundamental principles for effective banking supervision, Bank Al-Maghrib carried out a self-assessment of the banking regulatory framework to identify gaps and reforms to be undertaken.

The BAM regulation stipulates: "The PD/LGD method, which consists in applying the provisions of the internal ratings approach relating to the category of exposures companies", Bank Al-Maghrib (2010).

This regulation is only a transposition of the prudential rules resulting from the Basel II Agreement, in particular Pillar 1.

\section{Data and Methodology}

We have examined the 74 companies listed on the Casablanca Stock Exchange for the period from January 2, 2014 to December 31, 2014.

The application of structural models requires data that is often difficult to access. These data can be grouped into two categories: business data and market data.

In order to homogenize the selected sample as much as possible, to make it sufficiently representative and to avoid a bias of selectivity, Selection criteria:

1) The companies listed on MADEX (Moroccan Most Active Shares Index) are selected as a stock index composed of the most active stocks on the Casablanca stock exchange.

2) Companies selected in which the number of shares forming the capital is large enough suffered. In addition, each company with an asset volume of less than 15 million US dollars was removed from the sample.

3) In order to avoid a selectivity bias, the main market and development firms, which have the same sector of activity, were selected. The reason is that compa- 
nies must be a market of pure and perfect competition.

4) The choice has been made to introduce only companies that publish balance sheets Consolidated, and report their ratios and credit quality, as these will be the key figures of our study.

These selection criteria considerably reduced the starting sample, especially as information on financial and accounting ratios and loans are often unavailable. Consequently, a large number of companies were excluded. Our sample has decreased from 74 to 22 companies listed on the Casablanca Stock Exchange. We use company data to calculate market value, market data to estimate average and volatility.

Many methods have been proposed to predict credit risk. The most commonly used technique is scoring credit from discriminant analysis. This operation is finalized by the commitment of a score function that helps decision-making in the granting of credits. Numerous studies have been based on discriminant analysis (Altman, 1968; Altman et al., 1977; Conan \& Holder, 1979). However, the method of discriminant analysis has been criticized by several author (Deakin, 1972) because the validity of the results found by this technique depends on their restrictive assumptions, the normality of the distribution of each of the variables selected and the hypothesis of the independence between them. In order to overcome the shortcomings of the discriminant analysis method, other models of risk analysis have emerged.

Structural models are models of credit risk where a given firm is considered to be in default, when the value of its assets is no longer sufficient to meet its debt. In this approach initiated by Black \& Scholes (1973) and Merton (1974), the value of the debt is evaluated using the theory of options: the company's action and its debt appear as derivatives on the total value of its assets. The popularity of this model allowed the dissemination of Merton's ideas and transformed into a few decades the vision of credit risk.

The choice of the structural approach to credit risk (also called the firm's model) is generally used for the determination of probabilities of default. This probability depends on the quality of the initial credit, the longevity of the debtor and, above all, its current and future financial capacity.

The basic hypothesis of the Black-Scholes-Merton model is that the assets of a firm $X_{0}$ follow a stochastic process in continuous time (geometric Brownian motion), and that the defect is realized if $X_{0}$ crosses the fault barrier. The latter can be regarded as the recovery value in case of default.

\subsection{Modeling}

The Brownian geometric motion is a process of the form:

$$
X_{t}=X_{0} * \mathrm{e}^{\left[\sigma B_{t}+\left(\mu-\frac{\sigma^{2}}{2}\right) * t\right]}
$$

where $X_{0}$ Refers to the starting value of assets, $B$ is Brownian geometric standard, $\mu$ and $\sigma$ are Two constants representing respectively the variation and the 
volatility of the assets, and $t$ is refers to time.

From equation (6) we can draw:

$$
\ln \left(X_{t}\right)=\ln \left(X_{0}\right)+\sigma B_{t}+\left(\mu-\frac{\sigma^{2}}{2}\right) * t
$$

So

$$
\ln \left(X_{t+d t}\right)-\ln \left(X_{t}\right)=\sigma\left(B_{t+d t}-B_{t}\right)+\left(\mu-\frac{\sigma^{2}}{2}\right) * d t
$$

$\left(B_{t+d t}-B_{t}\right)$ Follows a normal centered distribution of variance $d t$ which will be noted $\varepsilon(0, \sqrt{d t})$. The Equation (8) is therefore written;

$$
\ln \left(\frac{X_{t+d t}}{X_{t}}\right)=\sigma * \varepsilon(0, \sqrt{d t})+\left(\mu-\frac{\sigma^{2}}{2}\right) * d t
$$

So

$$
\left.X_{t+d t}=X_{t} * \mathrm{e}^{\left[\sigma * \varepsilon(0, \sqrt{d t})+\left(\mu-\frac{\sigma^{2}}{2}\right) * d t\right.}\right]
$$

The transition from $X_{0}$ to $X_{1}$ is done using Equation (10).

\section{The Parameters of the Model}

The volatility of assets $(\sigma)$ : Under structural models, asset volatility can be estimated on the basis of the standard deviation of the annual change in the value of assets.

Determination of the Market Value of Assets: To determine the market value of a firm across the financial market (Table 2), the most commonly used method is VWAP (The Volume-weighted average price). This is the average price of shares traded during a given period. It is obtained by reporting the total value of the exchanges for that share over that period on the total number of shares exchanged over that period. By definition:

Company value $=\mathrm{VWAP} *$ number of shares

\subsection{Methodology for Developing Score Models Edward I. Altman's Model}

The basic idea is to determine from the accounts of companies, ratios which are advanced indicators of difficulties encountered by them. The final decision is made through studying all the ratios that make up the score function. This provides a quick answer on the quality of the borrower. The ratios are aggregated into a function, called $\mathrm{Z}$ or score function, which allows giving each company a Score.

These techniques are built up in a fairly conventional way based on balance-sheet data. The first methods of scoring were largely derived from financial analysis and were based on basic financial ratios in limited numbers. However, these methods have evolved into more complexity in order to try to obtain more reliable and precise scores, notably taking considering sector specificities. One distinguishes, among others, the model of Edward I. Altman and the discrimi- 
nating analysis.

Discriminant analysis is favoured by score constructors. It is a classification model based on data analysis, a statistical technique which consists in reclassifying the borrowers into three groups (default, tolerable defect and absence of default) and to look for all the variables (ratios) which allow for predicting the best, which has been lacking (in the past).

In the case of a three-group classification, discriminant analysis can be reduced to regression analysis. The discriminant function (11) is presented as a linear combination of these variables $\left(X_{i}\right)$.

Hence, the following statement:

$$
Z=1.2 X_{1}+1.4 X_{2}+3.3 X_{3}+0.6 X_{4}+1.0 X_{5}
$$

The score obtained in these models is used not only to decide whether to grant credit but also serves as an indicator of the risk level.

\subsection{Calculation Method}

To calculate the probabilities of default, Monte-Carlo method was chosen, given the difficulty of finding the analytical solution. This method allows generating fault time scenarios required for the calculation of losses for a given tranche.

The default occurs if the value $X_{1(i)}$ with $i=1,2,3, \cdots, n$, is less than the value of the debt at less than one year and therefore the probability of default is obtained by dividing the number of scenarios or $X_{1(i)}<$ the amount of short-term debts by the number of scenarios $\mathrm{n}$, graphically the fault can be represented like Figure 1.

The two parameters "dt" and " $n$ " are chosen so that their variations do not affect the calculated probabilities of defects. The graphs below show how the probability of default varies as a function of these two parameters.

Initially, the " $\mathrm{dt}$ " was set at a number of values for a portfolio company to detect the impact of the number of scenarios on the calculated probability of

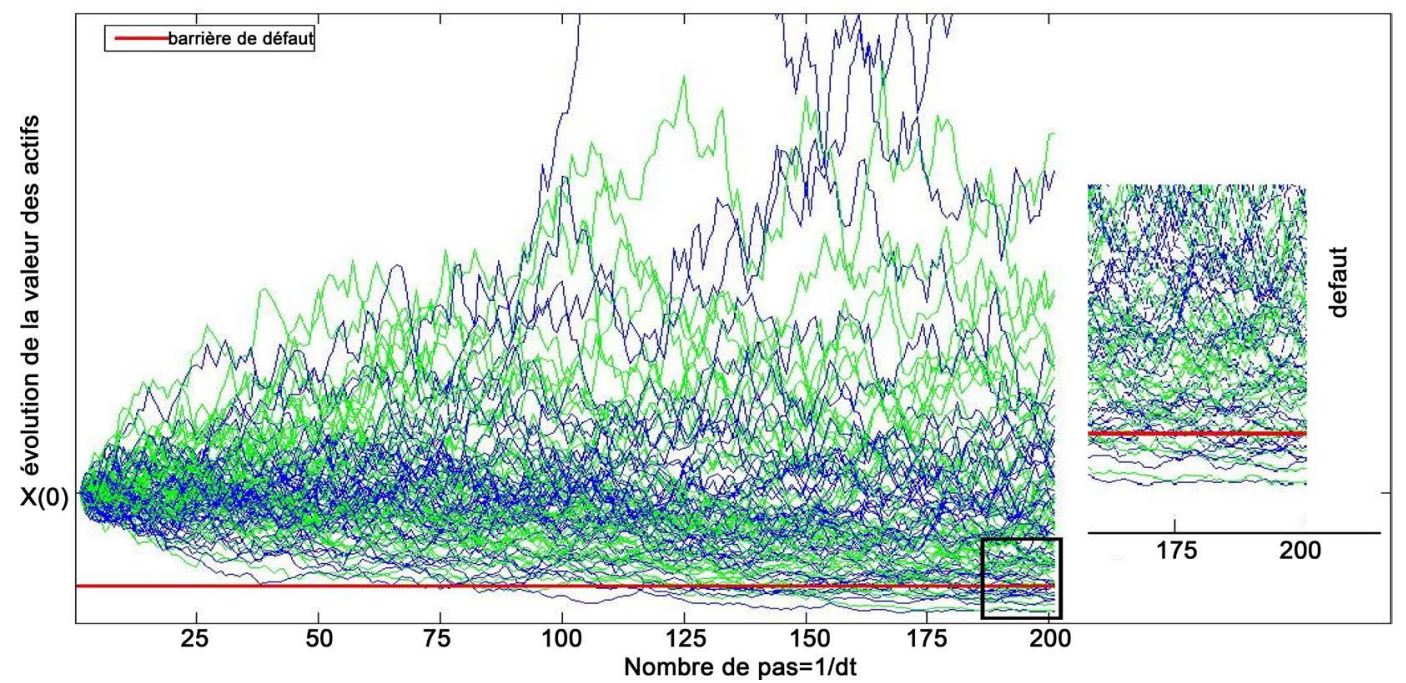

Figure 1. Simulation of default using the Monte-Carlo method. 


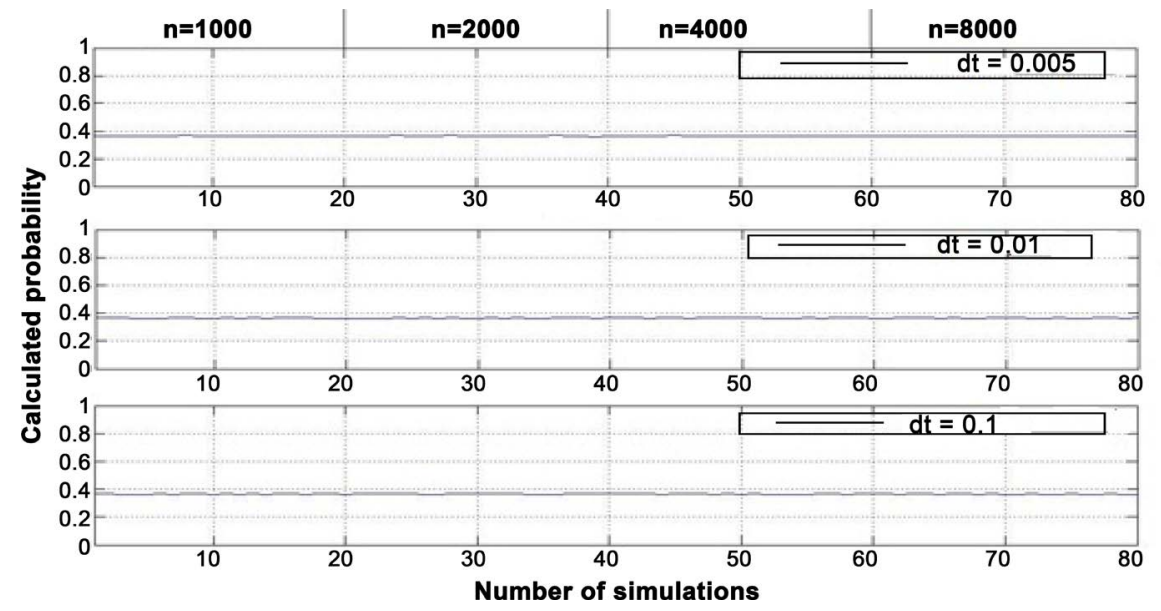

Figure 2. Influence of the number of scenarios on the calculated PD.
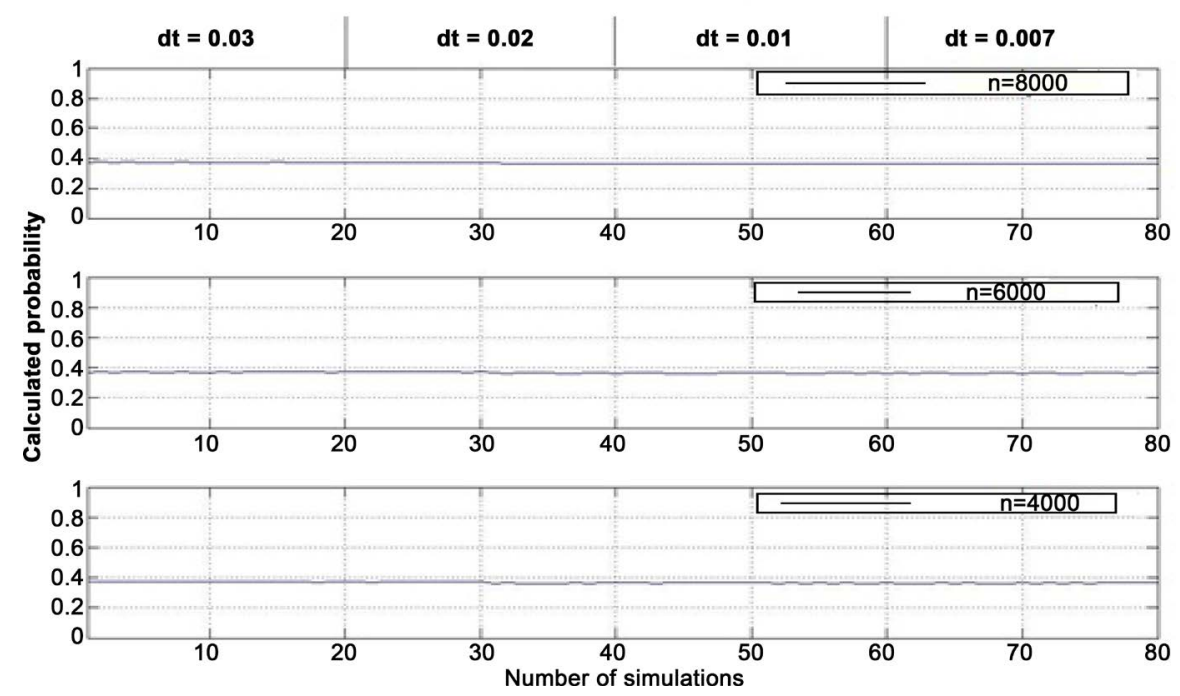

Figure 3. Influence of the number of steps on the calculated PD.

default (Figure 2). Then, as a function of the results obtained, the number of scenarios will also be fixed at a certain number of values and the " $\mathrm{dt}$ " will be varied (Figure 3 ) to arrive at an optimal torque (dt, n).

It is found that the couple $(0.005,8000)$ gives a probability that is stable, and which can be discarded $\mathrm{dt}=0.01$ and $0.1, \mathrm{n}=1000,2000$ and 4000 .

To maintain this stability, we will fix the number of scenarios and vary the "dt" the results are as follows:

It can be seen from the reading of the graphs that the torque $(0.005,8000)$ remains optimal and therefore will be chosen.

\section{Statistical Data and Description}

The choice of the concept of failure is not sufficient. We must add the one of temporal horizon.

A credit note cannot be given without specifying a time horizon. We know that every business can go bankrupt one day. The whole question for credit 
evaluation is: when? This is why there is often an aspect of implicit anticipation in the creation of a credit note. This aspect of anticipation is linked to the choice of a time horizon which makes it possible to determine a palette of reasonable scenarios for the evolution of the variables of interest. It is not simple to make short-term expectations or make long-term expectations. It is possible, however, to predict short-term bankruptcy than long-term bankruptcy because credit risk is increasing over time. Serious credit rating agencies issue both short-term (12-month) credit notes and long-term credit ratings. And insofar as short-term forecasting uses a narrower range of changes in interest variables, short-term rating scales contain fewer steps than long-term ones, and banks need to estimate the probability of default of one year for each risk category. This is why, in our case, we have chosen a time horizon from January the $2^{\text {nd }} 2014$ to December $31^{\text {st }} 2014$.

The calculation of the market values of the companies with their averages and their volatilities (Table 2).

Table 2. Market value, volatility and return on assets.

\begin{tabular}{|c|c|c|c|}
\hline Companies & Market value in DH & Average & Standard deviation \\
\hline ADDOHA & $17,706,200,710.00$ & -0.14 & 1.49 \\
\hline COLORADO & $644,716,290.00$ & 0.18 & 2.38 \\
\hline BMCE & $37,739,595,080.00$ & 0.04 & 0.85 \\
\hline STROC & $166,620,620.00$ & 0.34 & 3.08 \\
\hline SONASID & $4,064,836,330.00$ & 0.08 & 2.07 \\
\hline SAMIR & $3,648,036,630.00$ & 0.00 & 2.55 \\
\hline SAHAM & $4,045,281,890.00$ & 0.05 & 2.49 \\
\hline MICRODATA & $241,827,530.00$ & 0.11 & 2.62 \\
\hline MANAGEM & $11,509,271,710.00$ & -0.04 & 2.01 \\
\hline LBV & $3,485,079,480.00$ & -0.01 & 2.00 \\
\hline LAFARGE & $26,444,996,840.00$ & 0.13 & 1.84 \\
\hline IAM & $92,234,115,910.00$ & 0.10 & 0.80 \\
\hline HPS & $275,057,560.00$ & 0.07 & 2.43 \\
\hline HOLCIM & $8,876,921,190.00$ & 0.22 & 2.23 \\
\hline DISWAY & $390,404,820.00$ & 0.16 & 2.06 \\
\hline DH & $2,726,076,680.00$ & 0.01 & 1.97 \\
\hline CTM & $353,237,380.00$ & 0.23 & 1.88 \\
\hline $\mathrm{BCP}$ & $34,112,205,240.00$ & 0.05 & 1.03 \\
\hline AWB & $17,571,375,330.00$ & 0.04 & 1.76 \\
\hline ATL & $3,869,664,970.00$ & 0.00 & 1.93 \\
\hline ATH & $4,154,387,140.00$ & 0.04 & 1.76 \\
\hline ALLIANCE & $5,597,866,670.00$ & -0.21 & 1.37 \\
\hline
\end{tabular}


From Table 2, it can be seen that the lower the volatility of an asset, the greater the risk of investing in that asset in relation to high volatility, and hence the higher the expectation of gain (or risk Loss) will be significant, which affects the market value of a business.

\section{Results}

The calculation of the default probabilities generated the following results (Table 3) using the Monte Carlo method, with a number of scenarios equal to 8000 and a time step equal to 0.005 .

After calculating default probabilities, it is noted that the SAMIR, a petrochemical firm, has a high probability of default due to several elements, among which the non-optimal management of the high volatility of oil prices. The second element is the absence of a hedging contract and the final element is the use of certain distributors for the direct importation of refined products. For the company STROC, we can explain this underperformance by means of payment

Table 3. The probabilities of default of companies.

\begin{tabular}{|c|c|c|}
\hline Companies & Barrier of default in DH & Probabilities of default \\
\hline IAM & $17,533,000,000.00$ & 0.03 \\
\hline LAFARGE & $327,643,000.00$ & 0.06 \\
\hline SAHAM & $9,606,000.00$ & 0.11 \\
\hline BMCE & $10,552,802,000.00$ & 0.13 \\
\hline ALLIANCE & $408,772,502.00$ & 0.13 \\
\hline ATL & $77,134,986.00$ & 0.14 \\
\hline MANAGEM & $392,718,093.00$ & 0.25 \\
\hline ATH & $393,237,862.00$ & 0.31 \\
\hline HOLCIM & $355,360,267.00$ & 0.33 \\
\hline ADDOHA & $3,035,076,285.00$ & 0.36 \\
\hline HPS & $8,367,183.00$ & 0.40 \\
\hline $\mathrm{BCP}$ & $23,367,672,000.00$ & 0.53 \\
\hline CTM & $104,319,000.00$ & 0.56 \\
\hline DH & $605,254,158.00$ & 0.58 \\
\hline SONASID & $933,943,004.00$ & 0.61 \\
\hline COLORADO & $107,647,834.00$ & 0.64 \\
\hline AWB & $7,896,013,000.00$ & 0.65 \\
\hline DISWAY & $153,634,512.00$ & 0.69 \\
\hline MICRODATA & $35,164,950.00$ & 0.70 \\
\hline LBV & $3,077,615,459.00$ & 0.82 \\
\hline STROC & $426,648,264.00$ & 0.95 \\
\hline SAMIR & $11,034,419,169.00$ & 0.95 \\
\hline
\end{tabular}


Table 4. The probabilities of default by sector of activity.

\begin{tabular}{cc}
\hline Sector of activity & Probabilities of default \\
\hline Télécommunications & 0.03 \\
Assurance & 0.12 \\
Immobilier & 0.24 \\
Mines & 0.25 \\
Sociétés de Portefeuilles/Holdings & 0.31 \\
Banque & 0.39 \\
bâtiment et matériaux de construction & 0.41 \\
Transport & 0.56 \\
Distributeurs & 0.56 \\
Matériels. Logiciels et Services Informatiques & 0.60 \\
Ingénieries et Biens d'Equipement Industriels & 0.95 \\
Pétrole et Gaz & 0.95 \\
\hline
\end{tabular}

methods which provide for deductions of guarantees of large amounts without possibility of bonding during the project. The company is also suffering from high cash pressure due to additional work incurred but not yet invoiced and received. For Label'Vie, the difficult economic context marked by a deceleration in household consumption and a rise in competition (launch of the ATACADAO concept).

For the IAM Company, it is found that there is a low probability of default due to the significant improvement in the various indicators of usage, fleets and prices, in particular with regard to the mobile and Internet segments. For LAFARGE Morocco, it is evolving its business model to better meet the needs of its customers, by providing constructive solutions.

The aggregation above results by sector of activity (Table 4).

It should be noted that the oil sectors, engineering and industrial equipment are sectors that are more risky relative to other sectors because of the factors already mentioned to explain the high probabilities of firms.

The calculation of the Z-Scores by company and by sector of activity gave the following results (Table 5 and Table 6).

Risk is inherent in Telecommunication, Insurance, Housing and Banking. For the telecommunications sector, there are more than 40 million landline and mobile subscribers and 16 million Internet users. The development recorded by the insurance sector last years was favored by the main innovations: the formalization of bank-insurance, the reform of the guarantee fund and the strengthening of the insurance control system.

For the real estate sector, the realization of the fundamental objectives of the housing policy has maintained the development of this business.

The monopolization of the mining sector and the consolidation of the policies pursued by Morocco in the development of mining research, promotion of 
Table 5. Calculation of Z-scores of companies in the portfolio.

\begin{tabular}{|c|c|c|}
\hline Companies & Z-Score & Zone $^{\mathrm{a}}$ \\
\hline MANAGEM & 18.40 & \multirow{14}{*}{ Company is unlikely to default (Safe Zones) } \\
\hline HOLCIM & 16.20 & \\
\hline ALLIANCE & 9.10 & \\
\hline ATH & 9.10 & \\
\hline LAFARGE & 7.60 & \\
\hline COLORADO & 5.50 & \\
\hline IAM & 4.80 & \\
\hline SONASID & 4.60 & \\
\hline Addoha & 4.30 & \\
\hline $\mathrm{DH}$ & 3.90 & \\
\hline CTM & 3.50 & \\
\hline HPS & 3.50 & \\
\hline ATL & 3.20 & \\
\hline MICRODATA & 3.20 & \\
\hline SAHAM & 2.70 & \multirow{3}{*}{ Risk ignorance (Grey Zones) } \\
\hline BMCE & 2.70 & \\
\hline DISWAY & 1.90 & \\
\hline LBV & 1.70 & \multirow{5}{*}{ High risk (Distress Zones) } \\
\hline AWB & 1.60 & \\
\hline $\mathrm{BCP}$ & 1.10 & \\
\hline SAMIR & 1.10 & \\
\hline STROC & 1.10 & \\
\hline
\end{tabular}

a. The green color is above 3.0 indicates a firm is unlikely to enter bankruptcy, gray area is between 1.8 and 3.0 , and the red color is below 1.8 indicates a firm is headed for bankruptcy.

Table 6. The Z-Score by sector of activity.

\begin{tabular}{ccc}
\hline Sector of activity & Z-Score & Zone \\
\hline Mining & 18.40 & \\
Building and construction materials & 8.47 & \\
Housing & 6.70 & \\
Distribution & 5.40 & Sector companies are unlikely \\
Telecommunications & 4.80 & \\
Portfolio Companies/Holdings & 3.90 & \\
Transportation & 3.50 & \\
Insurance & 2.95 & \\
Hardware. Software and Computer Services & 2.87 & Risk tolerated (Grey Zones) \\
Banking & 1.90 & \\
Engineering and Industrial Equipment & 1.10 & High risk (Distress Zones) \\
Oil and Gaz & 1.10 & \\
\hline
\end{tabular}


mining projects, diversification of production, modernization of methods and means of extraction, and Vocational training policy have led to satisfactory results.

The banking sector is inevitable because it is in the nature of the bank to take risks. However, they must remain acceptable as a majority of the resources are contributed by the depositors and others by the donors, which will have to be repaid at one time or another. Banks are forced to be cautious. This is why the banking activities are increasingly supervised which explains the multiple recommendations of the Basel work.

Concerning hypothesis 1 , it is validated. Companies with a high market value have a low default risk. As for hypothesis 2, it is also validated. It is therefore wise to classify companies applying for credit according to their sector of activity.

\section{Conclusion}

In this paper, the IRBF (Internal Rating Based Foundation) approach has been applied in several steps, the most delicate is the determination of the probabilities of failure, a thing that has been done using a structural model, using the techniques of option evaluation for the calculation of probabilities of default assuming that the assets of the companies follow a geometric Brownian dynamics and that the defect occurs if their value falls below a barrier, which is in our case, debts to less than one year. The main purpose of the Altman Z-score method is to determine an overall score, enabling the identification of financially good companies and those with a higher risk of bankruptcy. The model is constructed by the most discriminating financial ratios.

The probabilities of default calculated for companies and sectors vary between $3 \%$ and $95 \%$, for companies in the telecommunications, insurance, housing and banking sectors, they have a low chance of going bankrupt, on the other hand the companies in the oil and engineering business and Industrial Equipment assets have a higher default risk. Validation of the calculated probabilities was carried out using Altman's Z-score which gave results very close to the calculated probabilities, which confirms the work performed in the part of the results.

The study could also be enriched by qualitative variables-which are not allowed by discriminant analysis-in order to increase the score and above all, to consider some events which are by definition, not quantifiable. These data (such as the number of bank incidents, for example) are not always easy to obtain.

Finally, the results of this paper can be extended for a longer time horizon. On the other hand, it would be interesting to extend the application of the IRBF method for unlisted companies.

\section{References}

Altman, E. I., Haldeman, R. G., \& Narayanan, P. (1977). ZETA ${ }^{\mathrm{TM}}$ Analysis a New Model to Identify Bankruptcy Risk of Corporations. Journal of Banking \& Finance, 1, 29-54. https://doi.org/10.1016/0378-4266(77)90017-6

Altman, E. I. (1968). Financial Ratios, Discriminant Analysis and the Prediction of Cor- 
porate Bankruptcy. Journal of Finance, 23, 589-609. https://doi.org/10.1111/j.1540-6261.1968.tb00843.x

Bank Al-Maghrib (2006). Circular 26/G/2006. Articles 11 to 16. The Allocation of Credit Risk Weights Following the Dissemination of External Credit Assessment Bodies. https://www.apsf.pro/docs/textes\%20leg\%20et\%20reg/26_g_2006.pdf

Bank Al-Maghrib (2010). Circular 8/G/2010. Articles 2, 27, 29, 36, 56, 58. Circular on Capital Requirements for Credit, Market and Operational Risk Coverage According to Internal Approaches to Credit Institutions.

https://www.apsf.pro/docs/textes\%20leg\%20et\%20reg/2010_circulaire_8g2010_approc hesavances.pdf

Basel Committee on Banking Supervision (1988). International Convergence of Capital Measurement and Capital Standards. https://www.bis.org/publ/bcbs04a.pdf

Basel Committee on Banking Supervision (2004). International Convergence of Capital Measurement and Capital Standards. https://www.bis.org/publ/bcbs107.pdf

Basel Committee on Banking Supervision (2011). Core Principles for Effective Banking Supervision. https://www.bis.org/publ/bcbs213.pdf

Basel Committee on Banking Supervision (2015). Standards Revisions to the Standardised Approach for Credit Risk. https://www.bis.org/bcbs/publ/d347.pdf

Black, F., \& Scholes, M. (1973). The Pricing of Option and the Corporate Liabilities. Journal of Political Economy, 81, 637-654.

https://www.cs.princeton.edu/courses/archive/fall09/cos323/papers/black_scholes73.pdf https://doi.org/10.1086/260062

Conan, J., \& Holder, M. (1979). Variables explicatives de performances et contrôle de gestion dans les PMI. Thèse de Doctorat en sciences de gestion, Université de Paris IX, Paris.

Deakin, E. B. (1972). A Discriminant Analysis of Predictors of Business Failure. Journal of Accounting Research, 10, 167-179. https://doi.org/10.2307/2490225

Merton, R. C. (1974). On the Pricing of Corporate Debt: The Risk Structure of Interest Rates. Journal of Finance, 29, 449-470.

http://www.people.hbs.edu/rmerton/Pricing\%20of\%20corporate\%20debt.pdf

Submit or recommend next manuscript to SCIRP and we will provide best service for you:

Accepting pre-submission inquiries through Email, Facebook, LinkedIn, Twitter, etc. A wide selection of journals (inclusive of 9 subjects, more than 200 journals)

Providing 24-hour high-quality service

User-friendly online submission system

Fair and swift peer-review system

Efficient typesetting and proofreading procedure

Display of the result of downloads and visits, as well as the number of cited articles

Maximum dissemination of your research work

Submit your manuscript at: http://papersubmission.scirp.org/

Or contact jfrm@scirp.org 